\title{
Prenatal Diagnosis and Genetic Analysis of X-Linked Immunodeficiency Disorders
}

\author{
JENNIFER M. PUCK \\ Division of Infectious Diseases and Immunology, The Children's Hospital of Philadelphia, \\ Philadelphia, Pennsylvania 19104
}

\begin{abstract}
Several congenital immunodeficiency diseases can exhibit X-linked inheritance, including agammaglobulinemia, severe combined immunodeficiency, Wiskott-Aldrich syndrome, $X$-linked lymphoproliferative syndrome, and $\mathrm{X}$-linked hyper-IgM syndrome. To date, the gene defects causing each of these $\mathrm{X}$-linked immunodeficiencies have not been identified, and the pathogenic mechanisms whereby mutations in these genes result in immunodeficiency are obscure. Although rare, all are associated with severe infections from early life and high morbidity and mortality. Regional localization of each of these gene defects on the $X$ chromosome has made possible carrier detection and prenatal diagnosis by linkage with polymorphic $\mathrm{X}$ chromosome markers in pedigrees demonstrating clear X-linked recessive inheritance. However, without a positive family history, it may not be possible to distinguish clinically between X-linked and autosomal forms. As a partial solution to this problem, it has now been established that female carriers of X-linked agammaglobulinemia, $\mathrm{X}$ severe combined immunodeficiency, and Wiskott-Aldrich syndrome can be identified by the pattern of $X$ chromosome inactivation in cell lineages targeted by each gene defect. As more families are offered the opportunity to use carrier detection and prenatal diagnosis, their decisions will reflect not only their personal experience with affected children with immunodeficiency, but also the clinical advances in bone marrow transplantation and immunomodulation. (Pediatr Res 33 (Suppl): S29-S34, 1993)
\end{abstract}

\section{Abbreviations}

CGD, chronic granulomatous disease HPRT, hypoxanthine phosphoribosyltransferase SCID, severe combined immunodeficiency WAS, Wiskott-Aldrich syndrome YAC, yeast artificial chromosome

Dr. Stiehm's article (1) reviews the tremendous mystery of the genetic immunodeficiency diseases. In the absence of direct clues about the nature of many immunodeficiency disease genes, the genetic approach of positional cloning may be the best way to find these genes and learn what role their products play in the immune system.

Table 1 lists the immunodeficiency diseases that we know map to the $\mathrm{X}$ chromosome and are involved with abnormal lymphocyte function. Why the $\mathrm{X}$ chromosome? That is because males, having only one $\mathrm{X}$ chromosome, will manifest effects from mutations on this chromosome because they will not be com-

Correspondence: Jennifer M. Puck, M.D., Associate Professor, Pediatrics, University of Pennsylvania School of Medicine, The Children's Hospital of Philadelphia, 34th Street and Civic Center Boulevard, Philadelphia, PA 19104. pensated for. As a pediatrician, this author has found it striking that male infants have more episodes of sepsis and more deaths from meningitis than females. One possible reason for this might be that there are alleles or variants of genes at some X chromosomal loci that would produce a partial immunodeficiency and might predispose male infants to infection. The implications of understanding the gene products at these loci may be broader than just the very rare diseases themselves. In this paper, the focus is on SCID, but other X-linked deficiencies are included to show where they may be similar to SCID and where they may differ.

\section{SCID}

SCID is a syndrome characterized by persistent infections, starting by age $6 \mathrm{mo}$, and failure to thrive. Laboratory investigations show absent mitogen responses, hypogammagiobulinemia and very low numbers of $T$ lymphocytes, although $B$ cells may be present. As with many syndromes, there are multiple genetic causes of this phenotype. However, as shown in Figure 1 , the excess of males affected with SCID as compared to females suggests that a large percentage of the cases can be attributed to genes on the X chromosome. Several different autosomal recessive defects are now known to produce the SCID phenotype in males and females, but these account for only about $15 \%$ of all SCID cases; the occurrence of girls born with SCID of unknown type indicates that there must also be undefined autosomal recessive mutations that produce this condition.

One of the challenges is to try to determine which cases of SCID can be attributed to the X-linked form and which cases are due to other forms. When a diagnosis of SCID is made, one must always ask for a family history and be alert for information about a SCID boy's maternal male relatives who might have been similarly affected. However, it is important to note that a negative family history does not rule out an X-linked mode of inheritance; X-linked lethal conditions like SCID show up as new mutations very frequently, and at least one third of the cases represent the first manifestation of a new mutation.

Women who are obligate carriers of SCID have completely normal immunity as judged by immunologic testing, and yet they are known to have one $\mathrm{X}$ chromosome that carries the gene defect that produces SCID. This is contrary to what one would expect based on another X-linked condition, CGD. In CGD, phagocyte killing is reduced in female carriers, and about half of their neutrophils fail to reduce nitro-blue tetrazolium dye. When one considers the difference between these gene defects, one has to think about the process of $X$ chromosome inactivation that occurs in all women. It is thought to be a dosage compensation mechanism; males have only one $X$ chromosome and females have two, and double doses of all the $X$ chromosome genes would not be desirable. So early in embryogenesis of a female, one or the other of the two X chromosomes is turned off permanently in each undifferentiated embryonic cell and becomes what we recognize as a Barr body in many mature female 
Table 1. X-linked immunodeficiencies with abnormal lymphocyte differentiation

Severe combined immunodeficiency (SCID)

Agammaglobulinemia (XLA)

Wiskott-Aldrich syndrome (WAS)

Lymphoproliferative syndrome (XLP)

Hyper-IgM syndrome

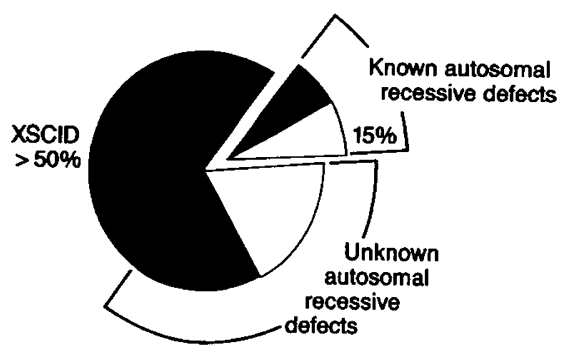

Fig. 1. Proportion of SCID caused by known and unknown gene defects occurring in males (shown in black) and females (shown in white).

tissues. As the cells from the embryo proceed to divide and differentiate, the $\mathrm{X}$ chromosome that is active will continue to produce transcripts and gene products; the inactive one sits on the sidelines and is mostly, though not completely, inactive. The turning off of one $\mathrm{X}$ chromosome (lyonization) is a random event in each embryonic cell so that the cells of mature female tissues consist of a mixture of cells with one $\mathrm{X}$ chromosome active and cells with the other X chromosome active (2).

In contrast, in the case of an X-linked defect that affects the subsequent development or survival of a cell lineage, a second phenomenon is superimposed on the lyonization pattern. In this situation, if there is a mutation in a gene, such as the X-linked SCID gene, on one of the two chromosomes of a female embryo, $\mathrm{X}$-inactivation will occur in exactly the same random fashion as it does in every female, but the subsequent development of a lymphocyte lineage in this woman is going to be altered. Cells that have the normal $\mathrm{X}$ active will proceed to develop into $\mathrm{T}$ cells completely normally, using a normal SCID locus gene product from the normal $\mathrm{X}$ chromosome. But when T-cell progenitors with the mutant $\mathrm{X}$ active arrive at the stage where that gene product is needed, the gene product will be missing; consequently, the cells will fail to develop. Therefore, the mature lymphocyte compartments of carriers have only the normal $\mathrm{X}$ active, instead of the normal, random mixture of cells with one or the other $\mathrm{X}$ active (3).

\section{ASSAY FOR X-INACTIVATION PATTERN}

Assays for determining a woman's X-inactivation pattern are needed to test this hypothesis. G6PD enzyme isotypes were first used for this purpose (4), and other methods include determination of methylation of particular $X$ chromosomal cytosine residues, at which methylation is correlated with activation status (5). We developed a functional assay selecting the human active $\mathrm{X}$ chromosome from a lymphocyte by fusing it to a hamster cell line deficient in HPRT, as shown in Figure 2 (3). Surviving cells after growth in selective medium containing hypoxanthine and azaserine must have a normal human HPRT enzyme to rescue the HPRT-deficient hamster fibroblast. This enzyme can only be made when an active human $\mathrm{X}$ chromosome is present. It turns out, almost always, that the inactive human $\mathrm{X}$ is lost, probably because the human cells divide more slowly than hamster cells, and the human chromosomes do not condense by the time mitosis is occurring.

By making a panel of independent hybrids that have the active $X$, selected from $T$ cells of a female, one can determine the $X$ inactivation pattern by analyzing which $X$ is present in each hybrid. This can be done by using any polymorphic marker that

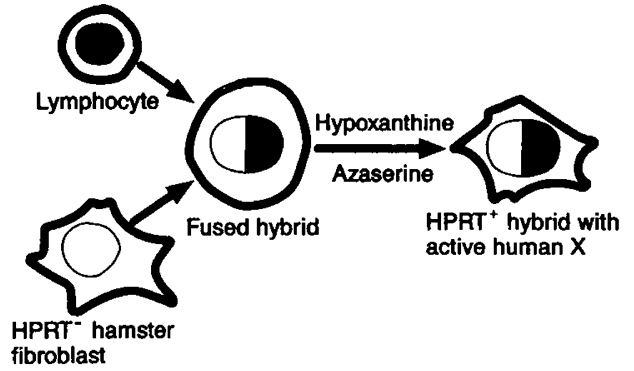

Fig. 2. Scheme for fusion of human lymphocytes to HPRT-deficient hamster fibroblasts, followed by selection of hybrid clones containing an active human $\mathrm{X}$ chromosome on a hamster background.

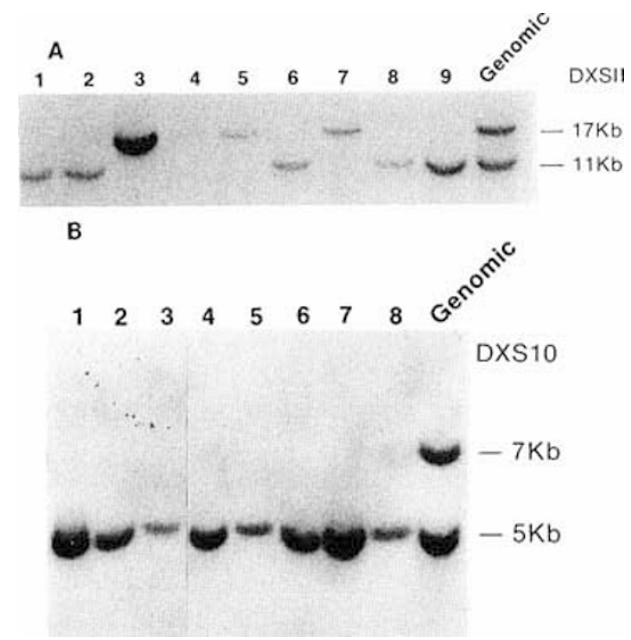

Fig. 3. Southern blot analysis of genomic DNA (right lane) and DNA from independent hybrids containing the active human $\mathrm{X}$ chromosome from $\mathrm{T}$ cells of a normal control female $(A)$ and an obligate female carrier of X-linked $\operatorname{SCID}(B)$.

can distinguish one $\mathrm{X}$ chromosome from the other. Formerly, a restriction fragment polymorphism was used, and hybrids were scored by Southern blot analysis, as shown in Figure 3, but we can now also use the new microsatellite polymorphisms detected by the polymerase chain reaction.

Figure $3 A$ shows an example of a normal $\mathrm{X}$-inactivation pattern, using the Southern blot technique, in a panel of hybrids made from $T$ cells of a control female fused to hamster cells. When digested with the enzyme TaqI and probed with a probe for the locus DXS11, DNA from one of her X chromosomes gave rise to a $17-\mathrm{kb}$ band, whereas the other showed an $11-\mathrm{kb}$ band, as shown in the genomic DNA lane. In the panel of hybrids, four have an active $X$ with the $17-\mathrm{kb}$ allele, whereas five have the $11-\mathrm{kb}$ allele. The random pattern seen is expected from a normal woman.

On the other hand, if the same kind of cell fusion is done with $\mathrm{T}$ cells from an obligate carrier of X-linked SCID, one sees a pattern such as the one shown in Figure $3 B$. This is a different polymorphism, at the locus DXS10, but it also shows two polymorphic bands on TaqI-digested DNA. This woman has the same $\mathrm{X}$ chromosome active in all T-cell hybrids shown; her active $\mathrm{X}$ is the one with the $5-\mathrm{kb}$ allele at this restriction fragment length polymorphism locus. That only one X chromosome can serve as the active $X$ in her T cells suggests that there is something wrong with the other $\mathrm{X}$ chromosome at a locus coding for a gene product required for $\mathrm{T}$-cell development.

\section{CELL LINEAGES TARGETED BY GENE DEFECT}

There is another important application for this test. If one views the female carrier as a chimera, she has a mixture of two 
kinds of cells in her bone marrow that are maturing into $\mathrm{T}$ cells, and one can use this technique to determine which cell lineages are primarily affected by the gene defect. For example, in carriers of X-linked agammaglobulinemia, the B cells have totally skewed $\mathrm{X}$-inactivation, but the $\mathrm{T}$ cells and all the other types of cells in the peripheral blood of these patients have normal, random $X$ inactivation (6). Thus, the only cell compartment that is primarily affected by the X-linked agammaglobulinemia gene defect is $B$ cells.

In SCID, hybrids were also made from cells from different bone marrow-derived lineages; $T$ cells, as discussed above, had skewed X-inactivation. The next question was: Would B cells also show this skewed $\mathrm{X}$-inactivation, implying a primary B-cell defect? Alternatively, the B-cell defect in SCID could be a secondary one, such as a lack of a diffusable T-cell helper factor or lymphokine. When we fused polyclonally activated B cells of SCID carriers, we found that their X-inactivation pattern was also skewed (7). Therefore, in X-linked SCID, the B cells as well as $T$ cells have a primary defect, and, even though the males affected with X-linked SCID may have abundant B cells, these cells are deficient when competing with normal $B$ cells in a carrier female. Additional studies using hybrids from SCID carrier monocytes showed that this cell lineage had random $\mathrm{X}$ inactivation. Thus, X-linked SCID is a lymphoid-limited gene defect and does not affect the rest of the cells in the bone marrowderived lineages.

Another X-linked disease, WAS, can be approached in the same way and was in fact the first disease to be assessed with Xinactivation (4). In WAS, every cell lineage in the bone marrow in carrier females shows skewed X-inactivation including B cells, $T$ cells, neutrophils, monocytes, and even erythrocytes and platelets. That makes sense in view of the phenotype of WAS, which usually presents with thrombocytopenia and problems with bleeding long before the immune problems become evident.

\section{GENETIC MAPPING}

A third benefit of determining X-inactivation patterns has been the extension of genetic mapping of immunodeficiency disease genes. Finding a gene by positional cloning requires excellent linkage data to define the region of a disease locus, after which gene candidates in that region are sought. In conditions that have until recently been lethal early in life, such as SCID, affected pedigree members are generally not available for linkage analysis, and the carrier status of females cannot be assigned unless they have affected offspring. For example, in the family shown in Figure 4 (8), if we were trying to do genetic mapping and did not have an X-inactivation carrier test, we would use people in whom the SCID gene can be followed from one generation to another, through the mother's X chromosome. There are three offspring representing phase-known meioses: one going from the mother in generation II to her carrier daughter

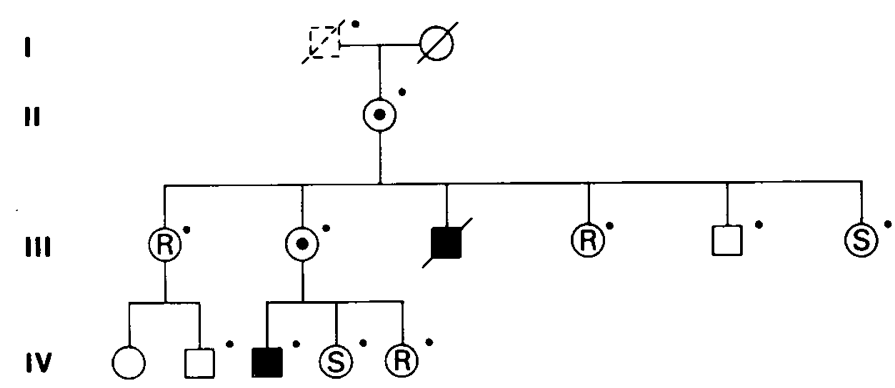

Fig. 4. Pedigree of a family with X-linked SCID. Squares represent males, circles females. Affected males are shown in black and obligate carrier females are indicated with an internal black bullet. Deceased individuals are indicated with diagonal slashes; dots to the right of symbols indicate persons available for genetic testing. $R$, random; and $S$, skewed T-cell X-inactivation patterns. in generation III; one from the mother to her normal son, whom we know got the non-SCID-bearing maternal X chromosome; and one from the carrier daughter to her affected son in generation IV, who survived with a bone marrow transplant. The affected boy in generation II died and is not available for gene mapping, and the rest of the females cannot be used for SCID mapping in the absence of a carrier test. However, once we do have a test for female carriers based on X-chromosome inactivation, we can assign carrier status to the females in the pedigree. The females in generation II include two with random X-inactivation patterns (R), who are therefore noncarriers, and one with a skewed pattern $(\mathrm{S})$, who is a carrier; similarly, carrier assignment has been accomplished in generation IV. We now have eight SCID-informative meioses instead of three. By this means, we have more than doubled the amount of linkage information obtainable from this pedigree and others that we have collected with the invaluable assistance of immunologists and geneticists around the country.

Several hundred polymorphic marker loci have now been identified on the human $\mathrm{X}$ chromosome. When the chromosomes pair up during female meiosis, chromosomal exchanges, or crossovers, occur. In women carrying an X-linked SCID mutation, the offspring receive a composite maternal $\mathrm{X}$ chromosome with some markers from the normal chromosome and other markers from the SCID chromosome. If one knows the offspring's phenotype, that is, whether this person inherited SCID or not, these random crossover events can be used to trace the disease gene relative to markers up and down the chromosome. Many laboratories have contributed to linkage studies of the Xlinked immune defects, which have all been localized to distinct regions of the $\mathrm{X}$ chromosome. The X-linked SCID locus is now known to be on the very proximal part of the long arm of the $X$ chromosome in the region called Xq13 $(8,9)$. Flanking markers have been defined above and below SCID so that one can make genetic predictions by analyzing which markers were passed by a carrier to her offspring.

Figure 5 shows an example of a family in which there was one boy affected with SCID and nobody else in the pedigree with any history of immune deficiency (10). This is the most common presentation of SCID, as a sporadic case in a male. The approach in this patient was to first study his mother and evaluate her Tcell $\mathrm{X}$-inactivation. We made 22 hybrids from the $\mathrm{T}$ cells of this woman, and they all turned out to have the same active X. Right then, we knew that she was a carrier of the X-linked form of SCID and therefore her son had the X-linked form of the disease. We also knew that the mother was at risk for having additional affected sons. Thus, when she became pregnant again and wanted to know if her new fetus would have SCID, an amniocentesis was performed. Karyotype analysis showed that the fetus was a

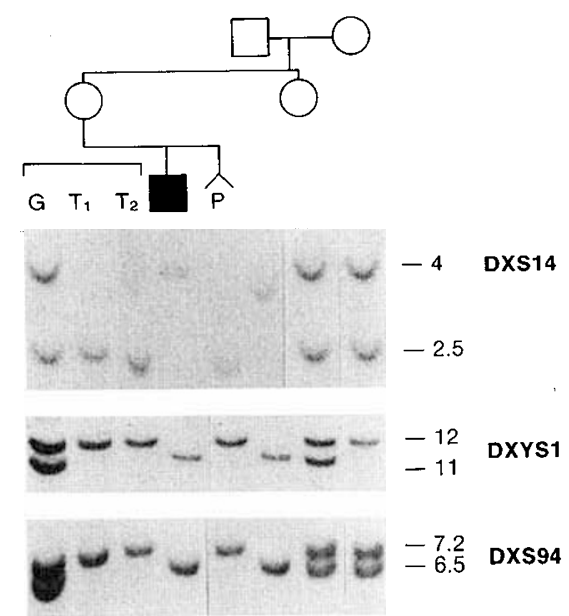

Fig. 5. Pedigree and Southern blot autoradiographs showing linked DNA marker analysis of a family with a single male affected with SCID. 
male and therefore at $50 \%$ risk of having SCID, so an analysis of linked DNA markers flanking the SCID region was undertaken to determine whether he had inherited his maternal non-SCIDbearing or SCID-bearing X chromosome.

As shown in the Southern blots in Figure 5, the mother's genomic DNA, in the lanes marked $G$, was heterozygous for DXS14, a marker on one side of the SCID locus, and DXYS1 and DXS94, on the other side of the SCID locus. All markers identified the maternal $\mathrm{X}$ chromosome that was active in T-cell hybrids (lanes $T_{1}$ and $T_{2}$ ) to have the opposite allele from the affected son (lanes below the black box). The fetus was shown to have the same alleles as the mother's hybrids and the opposite ones from the affected brother, which means that we would predict that he had inherited the normal copy of the gene at the SCID locus. This prediction was confirmed when the infant was born; his mitogen stimulation and T-cell surface marker studies were normal, and he has had no significant infections. One more interesting finding in this family was that the grandfather was found to have the same allelic pattern as the affected grandson. Evidently, he was the source of the SCID-bearing X chromosome that was passed through the carrier mother to the affected grandson; yet he is an elderly man who has never been sick a day in his life. The $\mathrm{X}$ chromosome that he gave to his daughter had a mutation that must have arisen in his germ cells, but was not present in his bone marrow lymphocyte progenitor cells.

When a test such as skewed X-inactivation is developed, one would like to be able to offer it to everyone who needs it, and it becomes very important to determine how specific is skewed $\mathrm{T}$ cell X-inactivation for diagnosing the carrier state for SCID. We have collected obligate carriers (we know they are carriers because they have had affected sons and affected relatives higher up in their pedigrees) and looked at their $\mathrm{X}$-inactivation. The paternal $X$ would be the normal $X$, so that is the one that is almost always active in the hybrids that we isolate. We have also studied normal individuals as controls to assess how skewed a normal woman could be and whether normal people might be skewed just by chance, not because they are SCID carriers.

We have adopted a model of $T$-cell $\mathrm{X}$-inactivation in which $\mathrm{T}$ cells of normal women are considered to be derived from a limited number of primordial bone marrow lymphoid progenitor cells, which have in turn come from a pool of embryonic cells with random $\mathrm{X}$-inactivation (11). The degree of skewing of the normal $\mathrm{T}$-cell $\mathrm{X}$-inactivation pattern depends on how many progenitor cells give rise to the T-cell lineage. If the number of precursors is very small, just two for example, then the chance that both precursors could have inactivated their $\mathrm{X}$ chromosomes in the same way is $25 \%$ for being all one way, $25 \%$ for being all the other way, and $50 \%$ for one of each. A small number of precursors gives a substantial proportion of outcomes that are totally skewed. However, if one started with $20 \mathrm{~T}$-cell precursors, then the $\mathrm{T}$-cell $\mathrm{X}$-inactivation ratio would be expected to be much more concentrated in the middle range. It would be exceedingly unusual to have totally skewed $\mathrm{X}$-inactivation, just as there is less than one chance in a million of flipping a coin 20 times and getting 20 heads in a row.

Our mathematical analysis of X-inactivation in normal women showed that the maximum likelihood number of $\mathrm{T}$-cell progenitors is 10 . Different women might have different numbers of precursors, but at least the range is somewhere between six and perhaps $20 \mathrm{~T}$-cell precursors (11). This has interesting implications in terms of bone marrow transplantation and for the normal physiology of bone marrow stem cell development.

Using our approximation of $10 \mathrm{~T}$-cell precursors for normals, we can express the results of X-inactivation testing for SCID carrier status as an odds ratio test. The test was evaluated by looking at how well it predicted carriers and noncarriers from the SCID pedigrees we have collected. We included women for whom we could independently assign carrier status by their inheritance of flanking genetic markers linked to the SCID locus. Of a total of 60 women at risk for being SCID carriers, none was misdiagnosed and only three came out in an indeterminant range. So although this test is not perfect, it is extremely useful.

There are other ways of assessing $\mathrm{X}$-inactivation, including methylation analysis, which compares cytosines that are specifically methylated or nonmethylated on inactive and active $\mathrm{X}$ chromosomes, respectively. Sites that are appropriate for study are the phosphoglycerate kinase gene, the HPRT gene, and perhaps other loci (5). Methylation analysis is certainly much easier than creating a panel of T-cell hybrids, which is very time consuming. Unfortunately, the methylation method does not lend itself to quantitation very well; if a patient clearly has random $\mathrm{X}$-inactivation, the analysis is very easy to read, but the question of how skewed a person can be is not easy to address with this test. Also, the methylation test cannot be used unless a woman happens to be heterozygous at one of the few available loci.

\section{FUTURE RESEARCH DIRECTIONS}

Closing in on the genes involved in immunodeficiencies is the next big step. Working with Dr. Robert Nussbaum's laboratory, we are screening a YAC library containing large DNA inserts from the human $\mathrm{X}$ chromosome with probes from the SCID region (12). The advantage of YAC clones is their insert size, averaging $300 \mathrm{~kb}$, which theoretically allows one to span a distance as great as 10 megabases (10 million bases), which is the order of the SCID region, with well under 100 of these clones. Our next step will be to search the YAC clones for transcripts that are expressed in human thymus and could be SCID candidate genes. Finally, the candidate genes must be evaluated for expression in the proper cell lineages and mutation in the DNA of boys affected with SCID.

\section{PRACTICAL APPLICATIONS}

Even before the genes for X-linked immunodeficiencies are found, what can we bring from our current level of understanding to improve the care of affected patients and their families? The $\mathrm{X}$-linked immunodeficiencies listed in Table 1 are the ones that have not been cloned, but these plus CGD and properdin deficiency, which have been cloned, have been localized on the $\mathrm{X}$ chromosome. Flanking markers are available for all these loci (13); thus, one can use linkage analysis to make genetic predictions in families known to have the X-linked forms of any of these diseases.

What can be offered to the family without a clear X-linked mode of inheritance that already has a child with SCID and wants to know the genetic options for future pregnancies? First, maternal $\mathrm{T}$-cell $\mathrm{X}$-inactivation can be used to identify the roughly $50 \%$ of these families in which the mother is a carrier of the Xlinked form of SCID, and the risk of SCID in future pregnancies can be evaluated and explained for all females who might carry the SCID mutation. Prenatal diagnosis by linkage can then be undertaken using amniocentesis or chorionic villus samples in these families. In the remaining families without clearly proven $\mathrm{X}$-linked inheritance, fetal blood sampling in the 2nd trimester can be used to diagnose SCID by T-cell surface markers and mitogen stimulation $(14,15)$.

We have now followed nine pregnancies of obligate and diagnosed carriers of X-linked SCID. These families are in the difficult position of having to decide among various reproductive options. On one hand, we are rapidly learning more about the management of immunodeficiencies; there are better ways to do bone marrow transplants and exciting new possibilities for treatment. On the other hand, SCID is still a devastating disease; bone marrow transplantation, particularly with a non-HLAidentical donor, carries a significant risk of mortality, and the long-term outlook is unknown. By following families who have made a decision to use prenatal diagnosis, we hope to gain understanding of how to help other families now and in the future. 
Table 2. Outcome of pregnancies at risk for X-linked SCID

\begin{tabular}{clc}
\hline $\begin{array}{c}\text { Number } \\
\text { monitored }\end{array}$ & \multicolumn{1}{c}{ Prenatal } & Postnatal \\
\hline 5 & XX females & Unaffected girls \\
2 & $\begin{array}{c}\text { XY males; flanking markers } \\
\text { from mother's } \\
\text { non-SCID- } \\
\text { bearing X chromosome }\end{array}$ & Unaffected boys \\
& XY males; flanking markers \\
& from mother's SCID- & Affected boys \\
& bearing X chromosome & \\
\hline
\end{tabular}

As shown in Table 2, of our nine pregnancies enrolled to date, five of the offspring were females, two were normal males, and two were males who inherited flanking markers from their mother's SCID-bearing X chromosome. Our predictions were correct in all cases. Two families decided to continue their affected male pregnancies and to have the babies born at centers where transplantation could be done in the neonatal period. One of the babies, cared for by Dr. Rebecca Buckley's team at Duke University Medical Center, had a sister who turned out to be an HLA-identical match. The other one was transplanted at the Children's Hospital of Philadelphia with maternal T-depleted bone marrow from the freezer that was left over from his older brother's successful transplant. Both children are over a year old now and have never had a significant infection. It is clear that infants with SCID do much better if they are transplanted before they develop infections and failure to thrive. Prenatal diagnostic studies are therefore useful not only for helping families decide whether to continue a pregnancy, but also to allow them to plan for neonatal bone marrow transplantation.

\section{REFERENCES}

1. Stiehm ER 1992 New and old immunodeficiencies. Pediatr Res $33: \mathrm{S} 2-\mathrm{S} 8$

2. Lyon MF $1966 \mathrm{X}$-chromosome inactivation in mammals. Adv Teratol 1:2554

3. Puck JM, Nussbaum RL, Conley ME 1987 Carrier detection in X-linked severe combined immunodeficiency based on patterns of $\mathrm{X}$ chromosome inactivation. J Clin Invest 79:1395-1400

4. Gealy WJ, Dwyer JM, Harley JB 1980 Allelic exclusion of glucose-6-phosphate dehydrogenase in platelets and T-lymphocytes from a Wiskott-Aldrich syndrome carrier. Lancet 1:63-65

5. Winklestein JA, Fearon E 1990 Carrier detection of the X-linked primary immunodeficiency diseases using $\mathrm{X}$-chromosome inactivation analysis. Allergy Clin Immunol 85:1090-1097

6. Conley ME, Brown P, Pickard AR, Buckley RH, Miller DS, Raskind WH, Singer JW, Fialkow PJ 1986 Expression of the gene defect in X-linked agammaglobulinemia. N Engl J Med 315:564-567

7. Conley ME, Lavoie A, Briggs C, Brown P, Guerra C, Puck JM 1988 Nonrandom $\mathrm{X}$ chromosome inactivation in $\mathrm{B}$ cells from carriers of $\mathrm{X}$ chromosomelinked severe combined immunodeficiency. Proc Natl Acad Sci USA 85:3090-3094

8. Puck JM, Nussbaum RL, Smead DL, Conley ME 1989 X-linked severe combined immunodeficiency: localization within the region $X \mathrm{q}$ 13:1-q21.1 by linkage and deletion analysis. Am J Hum Genet 44:724-730

9. De Sainte Basile G, Arveiler B, Oberle I, Malcolm S, Levinsky RJ, Lau YL, Hofker M, Debre M, Fischer A, Griscelli C, Mandel J-L 1987 Close linkage of the locus for $\mathrm{X}$ chromosome-linked severe combined immunodeficiency to polymorphic DNA markers in Xq 11:13. Proc Natl Acad Sci USA 84:7576-7579

10. Puck JM, Krauss CM, Puck SM, Buckley RH, Conley ME 1990 Prenatal test for X-linked severe combined immunodeficiency by analysis of maternal Xchromosome inactivation and linkage analysis. N Engl J Med 322:10631066

11. Puck JM, Stewart CC, Nussbaum RL 1992 Maximum likelihood analysis of human $\mathrm{T}$-cell $\mathrm{X}$ chromosome inactivation patterns: normal women vs carriers of X-linked severe combined immunodeficiency. Am J Hum Genet 50:742-748

12. Lee JT, Murgia A, Sosnoski DM, Olivos IM, Nussbaum RL 1992 Construction and characterization of a yeast artificial chromosome library for Xpter-Xc $27: 3$; a systematic determination of cocloning rate and $\mathrm{X}$-chromosome representation. Genomics 12:526-533

13. Davies KE, Mandel J-L, Monaco AP, Nussbaum RL, Willard HF 1991 Report of the committee on the genetic constitution of the X chromosome, HGMI 1 Cytogenet Cell Genet 58:853-966

14. Blakemore K, Scioscia A, Grannum P, Podell D, Hobbins J, Mahoney M 1987
The value of fetal blood sampling in the prenatal diagnosis of severe combined immunodeficiency syndrome. Am J Hum Genet 41(suppl):A267

15. Durandy A, Dumez Y, Griscelli C 1986 Prenatal diagnosis of severe inherited immunodeficiencies: a five year experience. In: Vossen J, Griscelli C (eds) Progress in Immunodeficiency Research and Therapy, Vol 2. Elsevier, Amsterdam, pp 323-327

16. Allen RC, Edwards AO, Caskey CT, Belmont JW 1991 Methylation status of an X-linked $\mathrm{HpaII}$ site 20 base pairs from a polymorphic trimeric repeat correlates with X-inactivation. Cytogenet Cell Genet 49(suppl):181(abstr)

17. Hendriks RW, Kraakman ME, Craig IW, Espansol T, Schuurman RKB 1990 Evidence that in X-linked immunodeficiency with hyperimmunoglobulin $\mathrm{M}$ the intrinsic immunoglobulin heavy chain class switch mechanism is intact. Eur J Immunol 20:2603-2608

18. Conley ME, Sullivan JL, Neidich JA, Puck JM 1990 X chromosome inactivation patterns in obligate carriers of $\mathrm{X}$-linked lymphoproliferative syndrome. Clin Immunol Immunopathol 55:486-491

19. Arveiler B, De Saint Basile G, Fischer A, Griscelli C, Mandel J-L 1990 Germline mosaicism simulates genetic heterogeneity in Wiskott-Aldrich syndrome. Am J Hum Genet 46:906-911

20. Hendriks RW, Mensink EJB, Kraakman MEM, Thompson A, Schuurman RKB 1989 Evidence for male X chromosomal mosaicism in X-linked agammaglobulinemia. Hum Genet 83:267-270

21. Puck JM, Siminovitch KA, Poncz M, Greenberg CR, Rotem M, Conley ME 1990 Atypical presentation of Wiskott-Aldrich syndrome: diagnosis in two unrelated males based on studies of maternal $\mathrm{T}$ cell $\mathrm{X}$ chromosome inactivation. Blood 75:2369-2374

\section{FLOOR DISCUSSION}

Dr. Sorenson: The possibility of early diagnosis of $\mathrm{X}$-linked SCID is very exciting. We had the chance to make an early diagnosis in one case because we knew the family history. We performed an outpatient bone marrow transplantation, and this child, who is now 3 y past bone marrow transplant, never spent a single day in the hospital. I think the type of work you are doing will probably lead to that advance, which has a tremendous impact on the cost of medical care for these children.

Dr. Schreiber: What you have described are beautiful, but seemingly painstaking, studies. In terms of using PCR (polymerase chain reaction), can you look at the X-inactivation pattern to define the defect, for example on the X-linked disorders that you have looked at so far?

Dr. Puck: Yes. First, we have modified the hybrid test so that we no longer use RFLP (restriction fragment length polymorphism) markers that require Southern blots. There is now a new class of PCR-based microsatellite polymorphic markers that can at first make one dizzy to look at, but after learning how to read them one can tell two X chromosomes apart very easily. After making a hybridization, we can harvest hybrid clones directly from the plates where they first appear, in about $10 \mathrm{~d}$, and put them straight into a PCR reaction. Since we do not have to grow up the quantities of cells to make DNA for a Southern blot, we save considerable time.

Second, there are now ways to look at methylation differences between active and inactive X chromosomes with PCR. A system for doing this has been described by Allen et al. (16). The microsatellite polymorphism is in the coding region of the Xencoded androgen receptor gene. The androgen receptor gene has a run of glycines, and different $\mathrm{X}$ chromosomes have different numbers of glycines, so PCR primers flanking those will amplify alleles of different sizes. There are also methylation-sensitive restriction enzyme sites in between the primers that can be cut with a methylation-sensitive enzyme and then amplified. If, after restriction enzyme digestion with $\mathrm{HpaII}$, amplification of only one allele occurs, a skewed X-inactivation pattern can be inferred.

Dr. Hirschhorn: I am a little confused, and this may be technical, but I think it is important because if you can skip the hybrid formation step it would be very useful. If you use PCR, don't you lose all the methylation?

Dr. Puck: Yes, PCR-amplified DNA is not methylated; but if one cuts the DNA before amplifying, the original PCR template DNA will consist exclusively of HpaII-resistant, or methylated, genomic DNA. But you bring up another important point, which is that the amplification is so phenomenal with PCR that quan- 
titation may be a problem, particularly after a large number of cycles. If both alleles amplify to the same degree, random $\mathrm{X}$ inactivation can be safely inferred. But if one allele predominates, then it is hard to know where the normal range stops and where the range for SCID carriers begins. Defining standards for the PCR methods is going to be essential; nonetheless, they are already useful as a screening step. If they give an ambiguous result, then the hybrids could be used.

Dr. Hirschhorn: Well, some of the newer methods may turn out to be suitable for quantitation.

Dr. Puck: I agree.

Dr. Stiehm: Several years ago, we sent your laboratory some samples on a large kindred with hyper-IgM syndrome, and the hybridization did not seem to be informative or did not work. Do you know why that was? Can you comment on hyper-IgM?

Dr. Puck: Working with Mary Ellen Conley, we have looked at two different families with hyper-IgM syndrome, and Hendriks et al. (17) published similar findings. Neither B cells nor $\mathrm{T}$ cells showed skewed $\mathrm{X}$-inactivation in carrier females. The diseases with skewed X-inactivation are XLA (X-linked agammaglobulinemia), SCID, and WAS. Furthermore, another X-linked immunodeficiency, the X-linked lymphoproliferative syndrome (XLP), does not show skewed X-inactivation (18). This may mean these are not developmental defects of a whole cell lineage. It could be a matter of end-stage expression, as in a carrier woman with CGD where those neutrophils are present but do not reduce NBT (nitro-blue tetrazolium) dye. Such a terminal differentiation function would not be expected to produce an Xinactivation difference. But we will not know for sure until these genes are cloned and their expression and function studied.

Dr. Cooper: My question concerns females with SCID. Are any of these patients being looked at for extreme lyonization? Would that be possible?

Dr. Puck: It would certainly be worth looking at them for extreme lyonization. What would also be very worthwhile would be to look at them for chromosome translocations or deletions, the kind of cytogenetic abnormality that has been a key to finding the defects of many different genes, including the gene for CGD. In that disease, a deletion led to the localization and identification of the gene. I would encourage people to do karyotypes at least on females with SCID, which seems to be clinically compatible with the X-linked form of the disease.

Dr. Schiff: XLA is one obvious example where only the B cell is affected, but there are some females who have the same phenotype in that they have extremely low numbers of $B$ cells. They present like the XLA males with early onset low immunoglobulins, and they also get the echovirus meningoencephalitis. We have always assumed that there must be some sort of a fine point mutation in the father's $X$ chromosome. Have you had a chance to look at any of those, or would you like to?

Dr. Puck: I have not, but Mary Ellen Conley has looked at one case, a girl who did not even have enough $\mathrm{B}$ cells to test for $\mathrm{B}$-cell $\mathrm{X}$-inactivation. Her $\mathrm{T}$-cell $\mathrm{X}$-inactivation was normal. If $B$ cells are not present, one cannot test their $X$-inactivation. One might ask if the $\mathrm{X}$-inactivation in the rest of her bone marrowderived cells or all tissues was skewed; in this case, it was not.
But again, it is still worth doing careful karyotypes of those girls. Maybe they would have a small deletion of the XLA region or some other chromosomal derangement associated with skewed $\mathrm{X}$-inactivation.

Dr. Schiff: Usually at least some B cells or pre-B cells can be obtained from the marrow and one could look at those.

Dr. Puck: It would definitely be very interesting.

Dr. Blaese: Using $\mathrm{X}$-inactivation with methylation, the Italians have found at least one WAS carrier who had three affected children, and yet she was totally random. Another situation that we see quite frequently in WAS is that the lineages that seem to be affected in the mother are variable. As you know, the initial studies by Gealy were on G6PD-deficient double heterozygous carriers and red cell heterozygosity was used as a way of detecting the initial heterozygosity, but you said the red cell lineage was affected in WAS. So there are apparently different levels of expression in different lineages.

Dr. Puck: You raise two very interesting questions, and I think they are different. A mother who has three affected boys with WAS but does not show the skewed X-inactivation in her blood cells could have a new germ line mutation. This has been described now in WAS (19), and in XLA (20), and we have just found a SCID family of this type, where the mutation is not in the maternal $T$ cells but is clearly in her germ line because it was passed on to multiple offspring. This points out the frequency of new mutations of X-linked disorders.

The other issue you bring up is the extent of skewing in different tissues, whether measured by G6PD heterozygosity or by any other method. Each different disease must be postulated to have its own degree of skewed $\mathrm{X}$-inactivation in each involved cell lineage. For example, in XLA, B skewing is quite extreme. In SCID carriers, we have seen occasional (about $0.5 \%$ ) $\mathrm{T}$-cell hybrids with the SCID-bearing $X$ active. We found the rate to be 10 times that in WAS (21), so the degree of skewing in WAS is not as complete. That makes $\mathrm{X}$-inactivation less specific a diagnostic modality for WAS, because there will be more overlap between carriers and normals in WAS.

Dr. Sacher: Are you suggesting that these are clonal disorders? We use the same markers to define clonality in hematologic diseases, and you have shown with some of the polymorphisms that these are clones that are expanding. So are these clonal disorders in the carrier mother?

Dr. Puck: No. These are genetic defects.

Dr. Sacher: But you have shown some of the polymorphisms to be consistent-expression of the PGK (phosphoglycerate kinase) for example.

Dr. Puck: You are right, the use of methylation has also been very helpful in showing, for example, that tumor populations all arise from the same cell. This was the first application of skewed $\mathrm{X}$-inactivation. But in carriers of X-linked SCID, the $\mathrm{T}$ cells are not clonal; there is a whole normal array of different clones. However, each of these clones has the same $X$ active because of negative selection against $T$-cell progenitors bearing an active mutant X. I postulate that, early in lymphocyte development, all the $\mathrm{T}$-cell progenitors with the mutant $\mathrm{X}$ active were deleted, but all the other clones survived. This is sort of a Darwinian negative selection, not an expansion of one clone. 